CUAD. CONTAB. / BOCOTÁ, COLOMBIA, 15 (37): 77-107 / ENERO-JUNIO 2014 / 77

\title{
Revelación on-line de la información financiera y no financiera de las entidades de la rama ejecutiva del orden nacional en Colombia*
}

doi:10.11144/Javeriana.cc15-37.roif

\section{Diego Fernando Católico-Segura}

Contador público, Universidad Nacional de Colombia.

Magíster en contabilidad y finanzas, Universidad de

Zaragoza (España). Docente-investigador, Universidad de

La Salle. Líder del grupo de investigación Responsabilidad, Rendición de cuentas y Transparencia.

Correo electrónico: dfcatolico@unisalle.edu.co

\section{Paola Andrea Gómez-Solano}

Contadora Pública, Universidad de La Salle. Miembro del semillero de investigación Responsabilidad, Rendición de cuentas y Transparencia.

Correo electrónico: gomezpaola0401@gmail.com

\begin{abstract}
Angy Johana Gómez-Díaz
Contadora Pública, Universidad de La Salle. Miembro del semillero de investigación Responsabilidad, Rendición de cuentas y Transparencia.
\end{abstract}

Correo electrónico: angygomezd@gmail.com

\footnotetext{
* Artículo derivado de un proceso de investigación que se adelantó bajo la modalidad de grado producción intelectual relevante, con el aval del Programa de Contaduría Pública de la Universidad de La Salle. El título de la propuesta de la modalidad de grado fue Revelación y divulgación de la información financiera y no financiera de las entidades pertenecientes a la rama ejecutiva del orden nacional en Colombia. La fecha de inicio del proceso fue julio de 2012 y la fecha de terminación julio de 2013.
} 
Resumen En Colombia, la rendición de cuentas se ha configurado como un mecanismo inherente al sistema de gobierno democrático, sustentada en la obligación de todo gestor público de informar y justificar sus actuaciones ante la sociedad y hacerse responsable de ellas. Esta rendición se puede realizar por medio de una serie de instrumentos como la revelación y divulgación de la información por Internet, lo cual ha sido contemplado por el gobierno nacional en la estrategia de gobierno en línea. De acuerdo con lo anterior, la presente investigación evalúa de manera empírica y descriptiva el grado de revelación y divulgación de la información financiera y no financiera, de las entidades de la rama ejecutiva del orden nacional nivel central en Colombia. Los resultados evidencian un grado de revelación intermedio de la información publicada en los sitios web de las entidades analizadas, lo cual limita el control social y configura un posible riesgo de corrupción al no permitir la visibilidad que se requiere para evaluar la gestión pública.

Palabras claves autor: control social; rendición de cuentas; gobierno en línea; revelación y divulgación de la información; rama ejecutiva

Palabras claves descriptor: control social; auditoría de cuentas; internet en administración pública; poder ejecutivo - Colombia

\section{Códigos JEL: M 41}

\section{Online Disclosure of the Financial and Non-financial Information of Executive Branch Entities on a National Level in Colombia}

\footnotetext{
Abstract Accountability has been constituted as an inherent mechanism of the democratic government in Colombia, based on the obligation of every public agent to report and justify before society his actions, and be held accountable for them. This accountability may be performed through a number of instruments such as the disclosure
}

and dissemination of information through the internet, which has been considered by the national government in the online government strategy. According to the foregoing, this research assesses in an empiric and descriptive manner the degree of disclosure and dissemination of financial and non-financial information of the central level executive branch entities in Colombia. The results show an intermediate degree of disclosure of the information published in the websites of the entities analyzed which limits social control and constitutes a possible risk of corruption, by not allowing the required visibility to assess public administration.

Key words author: social control; accountability; online government; disclosure and dissemination of information; executive branch

Key words plus: social control; auditing; internet in public administration; executive power - Colombia

\section{Divulgação on-line das informações financeiras e não financeiras das entidades do poder executivo de nível nacional na Colômbia}

Resumo Na Colômbia, a prestação de contas tem se configurado como mecanismo inerente ao sistema de governo democrático, sustentada na obrigação de todo gestor público de informar e justificar suas atuações ante a sociedade e assumir responsabilidade por elas. Esta prestação pode se realizar por meio de uma série de instrumentos como a divulgação e difusão da informação pela Internet, o qual foi contemplado pelo governo nacional na estratégia de governo on-line. De acordo ao dito, a presente pesquisa avalia de maneira empírica e descritiva o grau de divulgação e difusão das informações financeiras e não financeiras, das entidades do poder executivo do nível nacional central na Colômbia. Os resultados evidenciam um grau de divulgação intermédio da informação publicada nos sites das entidades analisadas, o qual limita o controle social e confi- 
gura um possível risco de corrupção ao não permitir a visibilidade precisa para avaliar a gestão pública.

Palavras-chave autor: controle social; prestação de contas; governo on-line; divulgação e difusão da informação; poder executivo

Palavras-chave descritor: controle social; auditoria; internet na administração pública; poder executivo - Colômbia

\section{Introducción}

La democracia es un sistema de gobierno que busca que las decisiones sean tomadas por los ciudadanos para su beneficio. Esta se puede dar en dos formas: democracia directa, la cual permite que los ciudadanos definan todos los aspectos legislativos y ejecutivos, y la democracia representativa, por la cual el pueblo elige a sus gobernantes para ser representados por estos (Przeworski, 1998).

Con este concepto, la gran mayoría de los países en el mundo ha establecido una democracia representativa, en la que ha estructurado sus formas de gobierno en principios, como la igualdad, que busca que todos los hombres sean iguales ante la ley; la libertad, por la cual todos los ciudadanos pueden hacer aquello que no les prohíba la ley; y la representatividad, por la cual los ciudadanos tienen derecho a elegir y a ser elegidos (Nohlen, 1984).

Para el caso colombiano, en 1991 se produjo un cambio constitucional, por el cual el país asumió la forma de gobierno de Estado Social de Derecho, Democrático y Participativo. De acuerdo con lo enunciado en la Constitución Política (CP, 1991), en este tipo de Estado prevalece el interés general de toda la ciudadanía y se deben garantizar la efectividad de los principios, derechos y deberes, y facilitar la participación de todos en las decisiones que los afectan y en la vida económica, política, administrativa y cultural de la Nación.

En el marco de los derechos y deberes, los ciudadanos colombianos pueden intervenir en los asuntos políticos y deben asumir una participación en la democracia, lo cual hace que el ciudadano entre a ser parte de lo que se dicte en asuntos públicos y ser los auditores de esa gestión, en pro de la Nación y a favor de obtener un bienestar común.

Debido a lo anterior, el artículo 270 de la CP faculta a la ciudadanía para que intervenga activamente en el control de la gestión pública al establecer que: "La ley organizará las formas y los sistemas de participación ciudadana que permitan vigilar la gestión pública que se cumpla en los diversos niveles administrativos". Dando cumplimiento a este artículo, y con el fin de facilitar la integración de los ciudadanos y servidores públicos, el Congreso de Colombia reglamentó uno de los instrumentos de control político, fiscal y social en la Ley 489 de 1998, la cual ajustó la organización y funcionamiento de las entidades del orden nacional y definió la rendición de cuentas como mecanismo de control en la gestión pública y de participación ciudadana (Art. 32).

La rendición de cuentas — definida por el Consejo de Política Económica y Social (CONPES, 2010)-es:

La obligación de un actor de informar y explicar sus acciones a otro(s) que tiene el derecho de exigirla, debido a la presencia 
de una relación de poder y la posibilidad de imponer algún tipo de sanción por un comportamiento inadecuado o de premiar un comportamiento destacado (p. 13).

Por tanto, la rendición de cuentas se configura como una obligación de los gestores públicos y como un mecanismo que los ciudadanos tienen para ejercer el control social, sobre aquellos a los que les han otorgado poder y manejo de los recursos públicos para brindar un bienestar general a toda la Nación.

Este mecanismo de control implica una serie de elementos, como la información (los gobernantes informan sobre sus decisiones), la justificación (los gobernantes explican sus decisiones u omisiones) y la sanción o el incentivo (los gobernantes deben asumir las consecuencias de sus actos) (Arboleda, 2008).

De estos elementos, se reconoce que el suministro o revelación de la información (financiera y no financiera) es el punto de partida de la rendición de cuentas, ya que esta permite identificar cómo fueron asignados los recursos y, a su vez, verificar si lo que se planeó se cumplió.

Para revelar la información en el marco de la rendición de cuentas, se han previsto instrumentos que permiten su divulgación o publicación, en el marco de la interacción entre los gestores y la sociedad; algunos de estos son las audiencias públicas, la interlocución por internet, la articulación de las entidades públicas, la publicidad y los mecanismos de seguimiento y evaluación (Arboleda, 2008).

Para posibilitar el uso de estos instrumentos, en la actualidad se cuenta con las tecnolo- gías de la información y la comunicación (TIC), lo cual ha entendido el gobierno nacional al plantear la estrategia de gobierno en línea. Los sitios web de las instituciones del Estado se configuran en un medio de acceso público a la información por parte de la sociedad, que permite la visibilidad de la gestión de los funcionarios para poder llevar a cabo el control social y mitigar las actuaciones no deseadas, como la corrupción.

A partir de lo planteado, el presente artículo busca indagar sobre el grado de revelación y divulgación de la información financiera y no financiera de las instituciones de la rama ejecutiva del orden nacional nivel central, en el marco de la estrategia de gobierno en línea, para posibilitar la obligación de rendir cuentas por parte de los funcionarios públicos a la sociedad colombiana.

Para cumplir el anterior propósito, el artículo inicia con la presentación de los conceptos y lineamientos frente a la rendición de cuentas y el gobierno electrónico, y hace énfasis en el suministro de la información en términos de su revelación y divulgación. Posteriormente, se presentan estudios previos que han evidenciado la información suministrada en los sitios web de las entidades del Estado en el ámbito internacional y nacional. A partir de lo anterior, se realiza un estudio empírico para indagar el grado de revelación online de la información en las instituciones de la rama ejecutiva del Estado colombiano, se configura la metodología, se analizan los resultados obtenidos y se exponen las conclusiones de esta investigación. 


\section{La rendición de cuentas y el gobierno electrónico en la administración pública}

Las sociedades democráticas se sustentan en que sus ciudadanos eligen a sus representantes para que estos velen por las necesidades y el bien general de la población. Por tal razón, el gobierno de este tipo de sociedades requiere que sus ciudadanos y ciudadanas se enteren, pregunten, intervengan y propongan sobre los asuntos públicos (DNP, DEPP, DAFF, Contraloría General de la República, OCASA, Corporación Transparencia por Colombia \& GTZ, 2008).

En esa relación entre gobierno y gobernados, el control social se configura como un medio que promueve la responsabilidad de la administración pública sobre sus acciones y su gestión (Cunill-Grau, 2007), lo que permite que la sociedad exija cuentas sobre los programas, actividades y planes, entre otros, realizados en el marco de la gestión pública, lo cual fortalece la confianza entre las instituciones y la ciudadanía, y mejora la eficiencia y la calidad de la administración pública (Departamento Administrativo de la Función Pública, 2011).

En este sentido, para que se dé una buena democracia, como se mencionó antes, es necesario que haya control social por parte de la ciudadanía, ya que este permite prevenir, vigilar, controlar y sancionar la gestión que realicen los funcionarios públicos, con base en sus resultados y la prestación de sus servicios.

El control social puede tener dos sentidos: en el primero, se reconoce el control social impulsado desde el mismo Estado, al establecer un orden social que puede ser coactivo y se lleva a cabo por las instituciones, o persuasivo que se hace por los medios de comunicación; el segundo tiene relación con el control ejercido desde la sociedad hacia el Estado en términos de la evaluación que se realiza sobre la ejecución de políticas públicas (Arias \& Vélez, 2010).

De no darse el control social, aumentarían los riesgos de corrupción, lo que trascendería a problemas de abusos de poder, manejo indebido de los recursos, clientelismo y politiquería, lo que genera que la legitimidad del Estado sea lesionada por el efecto perverso de esos problemas.

En Colombia, durante los últimos años, la interacción entre ciudadanos y Estado ha mejorado, ya que en sus inicios se caracterizaba por la falta de conocimiento e interés de los ciudadanos sobre los asuntos de la función pública y la ausencia de rendición de cuentas por parte del funcionario. Por lo anterior, se han desarrollado lineamientos como la Ley 489 de 1998, que estableció que todas las entidades y organismos de la Administración Pública tienen la obligación de desarrollar su gestión acorde con los principios de democracia participativa y democratización de la gestión pública. Para ello, el gobierno nacional podría realizar todas las acciones necesarias con el objeto de involucrar a los ciudadanos y organizaciones de la sociedad civil en la formulación, ejecución, control y evaluación de la gestión pública.

Hay mecanismos de participación de control social estipulados en la ley, ${ }^{1}$ que estable-

\footnotetext{
1 Las leyes que hacen referencia a estos mecanismos son la Constitución Política de Colombia de 1991 y la Ley 489 de 1998.
} 
cen el canal de comunicación deseado entre el Estado y sus gobernados, como el derecho de petición, la consulta popular, la iniciativa legislativa, la acción de tutela, las veedurías ciudadanas y la rendición de cuentas.

Estos mecanismos, en su conjunto, fortalecen el deber y el derecho de la participación por parte de la sociedad. En estos, se resalta la rendición de cuentas, que permite fortalecer el sentido de lo público, al posibilitar que la ciudadanía conozca y se apropie de los asuntos de interés general, ya que puede ejercer control, realizar una evaluación y obtener respuesta de sus solicitudes. De igual forma, la rendición de cuentas fortalece la gobernabilidad y genera confianza entre los gobernantes y la ciudadanía (Arboleda, 2008).

En este planteamiento, la rendición de cuentas es entendida como: "una práctica social y política de la interlocución entre los gobiernos y la ciudadanía y sus organizaciones con la finalidad de generar transparencia, condiciones de confianza entre ciudadanos y gobernantes y fortalecer el ejercicio del control social a la administración pública" (DNP, DEPP, DAFF, Contraloría General de la República, OCASA, Corporación Transparencia por Colombia \& GTZ, 2008). Con esta premisa, la rendición de cuentas se ha vuelto una exigencia generalizada en el mundo de la política democrática, ya que como lo plantea Andreas Schedler (2004): "todos estamos de acuerdo con que democracia implica rendición de cuentas" (p. 9).

Otros autores han planteado concepciones sobre la rendición de cuentas, con el sentido de existencia de una obligación por parte del gestor público, como es el caso de Juan Carlos Morón, citado por Germán Arboleda (2008), definiéndola como:

La obligación legal y ética, que tiene un gobernante de informar y explicar al gobernado sobre cómo ha utilizado los recursos que le fueron dados por el pueblo para emplearlos en beneficio del pueblo y no en provecho de los gobernantes de turno.

Adicionalmente, algunos autores van más allá de considerar la rendición de cuentas solo en la dimensión informativa y argumentativa. Andreas Schedler (2004) establece que:

La rendición de cuentas implica dos dimensiones básicas. Por un lado, la obligación de políticos y funcionarios de informar sobre sus decisiones y de justificarlas en público (answerability). Por otro, incluye la capacidad de sancionar a políticos y funcionarios en caso de que hayan violado sus deberes públicos (enforcement) (p.12).

En este sentido, se contempla que la rendición de cuentas incluye la responsabilidad del gestor público ante sus actuaciones y, por tanto, debe asumir premios o sanciones. Así lo ha entendido el Consejo Nacional de Política Económica y Social en Colombia, CONPES, en su documento 3654 de 2010, al definir que la rendición de cuentas:

Es la obligación de un actor de informar y explicar sus acciones a otro(s) que tiene(n) el derecho de exigirla, debido a la presencia 
REVELACIÓN ON-LINE DE LA INFORMACIÓN FINANCIERA Y NO FINANCIERA / H. MACÍAS, COMP. / 83

de una relación de poder, y la posibilidad de imponer algún tipo de sanción por un comportamiento inadecuado o de premiar un comportamiento destacado (2010, p. 13).

Vista de esta manera, la rendición de cuentas está compuesta por tres elementos que permiten prevenir y corregir las malas actuaciones de los gobernantes. El primero de ellos es la información, la cual se refiere a la disponibilidad, exposición y difusión de los datos, estadísticas, documentos e informes, entre otros, sobre las funciones a cargo de la institución o servidor, desde el momento de la planeación hasta las fases de control y evaluación (Grant \& Keohane, 2005).

El segundo elemento - la explicación o la justificación-se refiere a la sustentación de las acciones, a la presentación de los diagnósticos y las interpretaciones, a la exposición de los criterios utilizados para tomar las decisiones e, implica, por tanto, la existencia de diálogo y la posibilidad de incidencia de otros actores en las decisiones a tomar (CONPES, 2010).

Los dos primeros elementos - la información y la justificación - se utilizan para prevenir el abuso de poder y la malversación de los recursos, ya que implica, como lo menciona el CONPES (2010): "la posibilidad de una relación de diálogo y retroalimentación, constituyéndose en la base de la respuesta que deben dar los servidores públicos sobre sus acciones" (p. 15).

Finalmente, el tercer elemento - incentivos (premios y sanciones) - consiste en mecanismos de corrección de las acciones, de estímulo por su adecuado cumplimiento, o de castigo por el mal desempeño. Este es el instrumento por el cual los ciudadanos pueden juzgar a sus gobernantes. Los tres elementos se muestran en la figura 1.

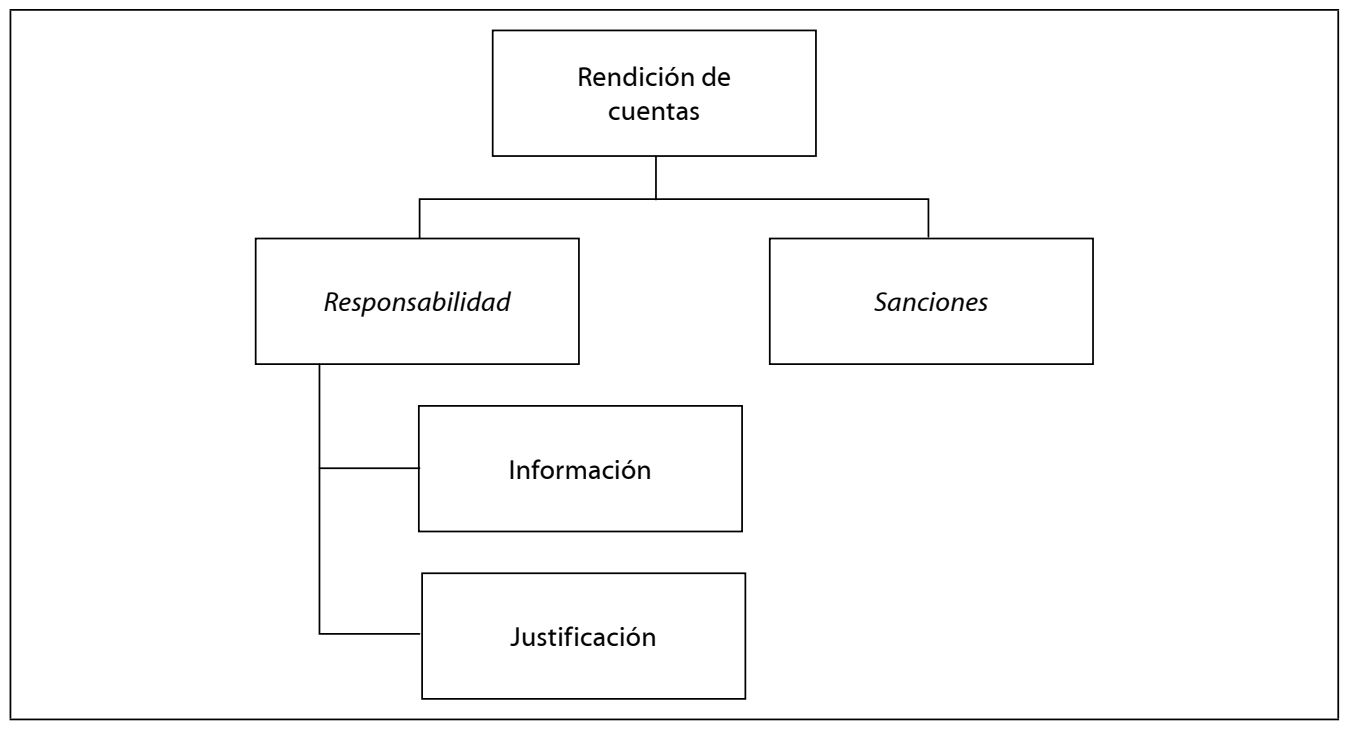

Figura 1. Esquema de los elementos de la rendición de cuentas Fuente: ¿Qué es la rendición de cuentas? (Schedler, 2004, p. 13). 
Si bien la rendición de cuentas contempla tres elementos, la información es el punto de partida y, por ende, el sustento del correcto desarrollo de los otros componentes, ya que no es posible exigir explicaciones y llegar a imponer sanciones o dar premios, cuando no se ha logrado tener la disponibilidad o el acceso a los datos, estadísticas, informes, entre otros, que son necesarios para establecer un diálogo entre los servidores públicos y los ciudadanos, con el fin de incentivar o castigar sus acciones.

Las instituciones tienen la obligación de generar, organizar, difundir y facilitar el acceso a la información, siendo esta veraz y confiable (CONPES, 2010). Por esto, es necesario revelarla y divulgarla. La revelación de la información se puede entender como el proceso de preparar y presentar la información relevante para la toma de decisiones y control de los recursos, y la divulgación hace referencia a la forma de publicar o poner a disposición la información para los usuarios (Católico, 2012; Gómez \& Católico, 2009).

En este sentido, en la Sentencia T-596 de 2002, la Corte Constitucional de Colombia ha señalado la obligación de las distintas dependencias de la Administración Pública de proporcionar la información necesaria para el ejercicio del control ciudadano, precisando:

En una democracia participativa, el derecho a acceder a la información (artículo 20, CP) constituye un instrumento indispensable para el ejercicio del derecho político fundamental a participar en "el control del poder político" (artículo 40, CP), de lo cual depende la efectividad del principio de responsabi- lidad política (artículo 133, CP), así como la materialización del principio de publicidad que rige la función administrativa (artículo 209 CP) (CONPES, 2010, p. 7).

De igual forma, en su artículo 78, la Ley 1474 de 2011 ajustó lo establecido en el artículo 32 de la Ley 489 de 1998, al establecer que:

todas las entidades y organismos de la administración pública tendrán que rendir cuentas de manera permanente a la ciudadanía, bajo los lineamientos de metodología y contenidos mínimos establecidos por el gobierno nacional, los cuales serán formulados por la comisión interinstitucional para la implementación de la política de rendición de cuentas creada por el CONPES 3654 de 2010.

Estos lineamientos reconocen de manera implícita la revelación y divulgación de la información, al mencionar los contenidos mínimos, que se entiende harán referencia a la información obligatoria y, a su vez, contempla el tipo de información a presentar (financiera o no financiera). Así mismo, al abordar la publicidad de la información, los lineamientos convocan a las instituciones del Estado a buscar los medios para posibilitar el acceso público.

En desarrollo de lo anterior, mediante la Directiva Presidencial 02 de 2000, el Decreto 1151 de 2008, el documento CONPES 3650 de 2010 y el Decreto 2693 de 2012, el gobierno nacional planteó que el país debería avanzar en el uso intensivo de las tecnologías de la información para prestar servicios a los ciudadanos y 
suministrar información, lo cual tendría alcance en todas las instituciones del orden nacional de la rama ejecutiva.

Estos lineamientos normativos se enfocan puntualmente en un concepto de gobierno electrónico o e-government sustentado en el uso de las tecnologías de la información y la comunicación, en particular internet, para el suministro de información y la prestación de servicios a la ciudadanía de una forma más conveniente, sencilla y accesible (Royo, 2008).

La estrategia de gobierno en línea contempla cinco fases para su realización: información, interacción, transacción, transformación y democracia. Para el desarrollo de estas fases, durante los últimos años, el Ministerio de Tecnologías de la Información y las Comunicaciones, MinTIC, ha emitido los manuales 3.0 (2011) y 3.1 (2012). El primero de ellos establece los lineamientos que deben seguir las entidades públicas en la implementación de esta estrategia en cuanto a los contenidos, procesos y procedimientos que se deben contemplar para posibilitar un canal de información idóneo, que propicie la participación de la ciudadanía en la gestión de cada institución. El segundo manual (3.1) sigue la misma línea de lo expuesto en el 3.0, pero su alcance va hasta las instituciones de la rama ejecutiva del orden nacional.

En el caso de la fase de información, de interés para este estudio, los manuales establecen la publicación de los datos generales de la institución, normatividad que rige a la entidad, la información financiera y contable, los lineamientos sobre su planeación, gestión y control, la contratación, trámites y servicios, y recurso humano, entre otros aspectos.
A partir de lo expuesto hasta este momento, bajo la forma de gobierno democrático, la rendición de cuentas se concibe como un mecanismo de control social sobre aquellos agentes que administran recursos públicos, pues de esa manera se posibilita la visibilidad de sus actuaciones, al tener acceso a la información mediante la estrategia de gobierno en línea, lo cual fortalece principios como la transparencia, la moralidad, la imparcialidad, la publicidad, la responsabilidad y la corresponsabilidad en los ejercicios de gobierno, lo que mejora las relaciones entre Estado y sociedad, ya que se comenzaría por impartir un Estado más comunitario, a partir de un gobierno que dé cuenta a quienes lo eligieron.

\section{Investigaciones previas}

La revelación y la divulgación de la información juegan un papel importante en la sociedad, ya que con ellas las personas pueden conocer e indagar sobre un tema en particular de la gestión de las instituciones públicas, lo cual ha sido objeto de estudio por distintos autores, que han reconocido que la publicación de la información por internet permite el acceso a ella a un número importante de usuarios sin ninguna restricción y en cualquier momento.

Una primera investigación es la realizada por Manuel Pedro Rodríguez-Bolívar, Antonio Manuel López-Hernández y María del Carmen Caba-Pérez (2005); esta abordó la divulgación de la información financiera gubernamental en internet en países sudamericanos y continentales europeos, evaluando, mediante un índice, 
aspectos sobre la información financiera, sus cualidades y diseño de los sitios web, que en conjunto permitieron medir el grado de divulgación de la información. De la evaluación se obtuvo como resultado que los países sudamericanos, en cuanto al acceso a la información presupuestal, alcanzaron uno de los más altos porcentajes de cumplimiento de los parámetros establecidos para la evaluación (93,75\%), con respecto a los países europeos $(67,50 \%)$.

Un estudio planteado por Vicente Pina, Lourdes Torres y Sonia Royo (2010) sobre los ayuntamientos/alcaldías de las principales ciudades y capitales de 15 países europeos, muestra que las TIC no han conseguido que las cuentas de las administraciones públicas en Europa sean más transparentes, es decir, no se ha logrado que la rendición de cuentas en lo referente a la información financiera, sea accesible a los ciudadanos para que sepan cómo se utilizan los recursos públicos.

Los resultados muestran que no todas las entidades locales facilitan en su página web la información financiera que deben presentar para cumplir con la legalidad vigente en sus respectivas jurisdicciones, pues alrededor del $40 \%$ de las ciudades divulgan el balance y la cuenta de resultados en su página web y, por otra parte, la presentación del presupuesto aprobado es bastante frecuente, pero en menor medida la del estado de ejecución presupuestal.

Otros estudios han abordado este tema con aplicación en países de manera individual, como en el caso expuesto por Alejandra Ríos y Guillermo Cejudo (2009), sobre la rendición de cuentas de los gobiernos estatales en México. En este se estudiaron principalmente cuatro procesos: la generación y sistematización de información gubernamental, la evaluación de actores, instituciones y políticas, la supervisión y vigilancia del adecuado uso de los recursos públicos y las medidas de prevención y sanción ante irregularidades en el ejercicio del gobierno. Para esta investigación, se solicitó directamente la información y se enviaron cuestionarios de preguntas cerradas a dependencias gubernamentales, órganos garantes del acceso a la información pública y entidades de fiscalización e investigación documental.

Los resultados obtenidos fueron que los ciudadanos mexicanos tienen pocos instrumentos para exigir cuentas a los gobiernos estatales y que, aunque existe legislación en la materia, no se garantiza la producción, sistematización y organización de esta información; además, la evaluación del desempeño gubernamental es débil y las instituciones encargadas del control y vigilancia de las entidades gubernamentales no cuentan con los recursos necesarios para esta labor y, además, los controles internos de los gobiernos no han logrado vincular los resultados de la evaluación con acciones concretas de mejora.

De igual forma, José Ángel Rivero, Leonor Mora y Sandra Flores (2007) realizaron un estudio de la rendición de cuentas por medio del e-gobierno en la administración local española, para evaluar el grado de información relacionada con la rendición de cuentas que ofrecen las entidades locales municipales por internet y de esa manera, obtener una imagen de transparencia de su gestión. Para esto se realizó un estudio empírico sobre las páginas web de los 22 ayuntamientos más grandes de España (por 
número de habitantes). Los puntos a evaluar se centraron en aspectos financieros de las instituciones y se obtuvo como conclusión que el uso de internet para facilitar información sobre rendición de cuentas, es escaso en la mayoría de los ayuntamientos; solo una institución utiliza su sitio web como medio para facilitar la información completa.

Otra investigación es la realizada por Sandra Cristina Riascos, Graciela Martínez-Giordano y Ómar Javier Solano-Rodríguez (2008), sobre el gobierno electrónico como estrategia de participación ciudadana en la administración pública en Suramérica — casos Colombia y Uruguay-; con base en un estudio de la Organización de las Naciones Unidas, se centra en las características principales del gobierno electrónico, como la información, la comunicación, los trámites, etc., que se pueden tener al servicio del ciudadano.

La anterior investigación reconoce que en Colombia se estableció el gobierno en línea en el año 2000, cuando se pretendió mejorar la eficiencia y transparencia del Estado. En el caso de Uruguay, la estrategia que se implementó fue la creación de la agenda del gobierno electrónico en 2005, para mejorar los servicios al ciudadano y la gestión del Estado. El análisis del estudio determinó buenos avances en el progreso que llevan estos países frente a sus políticas de gobierno electrónico para afianzar la confianza entre ciudadanos y el Estado, además de poder controlar y vigilar los recursos públicos entregados a la Nación.

Adicionalmente, el estudio adelantado por el Ministerio de Tecnologías de la Información y las Comunicaciones, MinTIC (2010), sobre los datos observados en 2009 con respecto a 198 entidades pertenecientes a los 27 sectores, ramas y/o organismos en Colombia, evidencia que frente a la divulgación de la información por internet, los distintos sectores presentan resultados diferenciados, resaltando los obtenidos por las entidades asociadas a la función pública, estadística y presidencia, y en un menor nivel la rama judicial, legislativa y las universidades públicas.

Finalmente, Diego Fernando Católico (2012) realiza la investigación Revelación y divulgación de la información financiera y no financiera de las Universidades Públicas de Colombia. Esta se focaliza en un sector de las instituciones públicas y, dados la metodología y los resultados, resultan múltiples criterios de interés para futuras investigaciones.

El objeto de este estudio fue vincular la rendición de cuentas con el uso del gobierno electrónico mediante el acceso a la información, para evaluar el grado de revelación y divulgación de la información financiera y no financiera de las universidades públicas. Esta investigación se realizó con un proceso empírico sobre la información revelada y divulgada para ser medible con un índice; de esta se obtuvo como resultado que los niveles de revelación y divulgación presentan un grado intermedio (59\%), lo que lleva a que el ejercicio de rendición de cuentas sea limitado, ya que los usuarios no cuentan con la información completa que les permita a los grupos de interés conocer la generación y uso de sus recursos, y el vínculo de estos con los procesos y resultados alcanzados académicamente por las instituciones. 
Como se puede observar, los estudios evidencian que la mayoría de las instituciones públicas, tanto en el ámbito internacional como en el nacional, cuenta con un sitio web en el que revelan cierto tipo de información, ya sea financiera y/o no financiera, con el objetivo de que la ciudadanía pueda consultar información de su interés y generar sugerencias, quejas o peticiones frente a ciertos aspectos que por parte de la entidad se revelen y divulguen. No obstante, la revelación de la información está en niveles intermedios, por lo cual las instituciones deben seguir trabajando para mejorar la comunicación entre el Estado y sus ciudadanos, a partir de la información publicada en sus sitios web.

De igual forma, los estudios han tenido alcance en distintos países, pero en el caso particular de Colombia, hace falta trabajar en aquellos que permitan evidenciar la revelación y divulgación de la información, al seguir los lineamientos previstos en la estrategia de gobierno en línea y profundizar en los distintos sectores. Esto último configura la intención del presente estudio, al abordar las entidades que componen la rama ejecutiva del orden nacional nivel central y reconociendo no solo información financiera, sino también aquella que complementa y da cuenta de las actuaciones en la administración pública.

\section{Metodología de la investigación}

El tipo de investigación a desarrollar es de corte empírico-descriptivo, en la medida en que se analiza el grado de revelación y divulgación de la información financiera y no financiera de las entidades de la rama ejecutiva del orden nacional en sus sitios web, de acuerdo con los requerimientos mínimos establecidos en el Manual 3.1, para la implementación de la estrategia de gobierno en línea en entidades del orden nacional.

A partir de lo anterior, la hipótesis del trabajo es:
H1: Las entidades de la rama ejecutiva del orden nacional nivel central logran altos ni- veles de revelación y de divulgación de la información financiera y no financiera, por medio de sus sitios web.

Esta hipótesis tiene sentido en la medida en que el acceso a la información es un derecho constitucional y una condición básica para la reducción de los riesgos de corrupción, pues eleva los niveles de transparencia en la gestión pública. A su vez, aporta elementos con respecto a la gestión de los recursos públicos y genera condiciones de fortalecimiento de la confianza de los diferentes actores en su relación con la administración pública, lo que se convierte en un aspecto clave para la gobernabilidad y la creación de capital social (Ministerio de las Tecnologías de la Información y las Comunicaciones, 2012).

La investigación se enfoca en las entidades suscritas a la rama ejecutiva del gobierno colombiano, que son las encargadas de aplicar las leyes (Farfán \& Gordillo, 2004). Las funciones principales de esta rama son las mismas asignadas al presidente de la República como jefe de Estado, jefe de gobierno y suprema autoridad administrativa. 
La rama ejecutiva se clasifica en orden nacional y orden territorial; estas a su vez, se dividen en el nivel central y descentralizado. Como objeto de estudio de esta investigación, se toman las entidades del orden nacional en el nivel central, dado que este tipo de entidades son las que mantienen la unidad nacional del país y no poseen una autonomía administrativa y financiera, ya que dependen de la autoridad suprema.

Para el desarrollo de esta investigación se reconoce la existencia de 45 entidades que conforman la rama ejecutiva del orden nacional nivel central, la cual está compuesta por la Presidencia de la República, la Vicepresidencia de la República, 16 ministerios, ocho departamentos administrativos, una superintendencia, 10 consejos superiores y ocho unidades administrativas especiales (ver Anexo 1). No obstante, la indagación de información se realiza en 30 entidades, que cuentan con sitio web.

Sobre este conjunto de instituciones, se realiza una evaluación del grado de revelación y divulgación de la información que se exige según lo establecido en la estrategia de gobierno en línea en su componente de información, el cual comprende datos generales (15 indicadores); normatividad, política y lineamientos (4 indicadores); información financiera y contable (4 indicadores); planeación, gestión y control (20 indicadores); contratación (3 indicadores); trámites y servicios (2 indicadores) y recurso humano (6 indicadores).

Para la evaluación de las entidades, se tomaron adicionalmente dos indicadores en el aspecto de información general del Manual 3.0, que fueron eliminados en la nueva versión y se consideran importantes para el conocimiento de la ciudadanía. Estos indicadores tratan sobre la fecha de la más reciente actualización de la página y/o documentos y si el portal de la entidad ofrece como mínimo en idioma inglés los contenidos relacionados con información básica de la entidad. Así mismo, se incluyeron tres indicadores en los aspectos de información financiera y contable, y dos indicadores en planeación, gestión y control, que son propuestos por los autores de la presente investigación, dada su importancia para los usuarios de la información en la evaluación y control de la gestión pública (anexo 2).

Todos los indicadores anteriormente expuestos se califican entre 0 y 1 , siendo "cero" cuando no cuenta con la información y "uno" cuando cuenta con la totalidad. No obstante, a los datos que cuentan con la información parcial, para algunos indicadores, se les otorga un valor 0,5 "cero punto cinco" (anexo 2).

De la evaluación realizada se obtiene una nota global no ponderada, que permite determinar el grado de revelación y divulgación de la información por cada uno de los indicadores analizados. De igual forma, se genera un ranking de las entidades, que permite observar aquellas que presentan mejores resultados en términos de la revelación y divulgación. Esto último, con el fin de incentivar a las entidades para que cumplan la estrategia de gobierno en línea y, de esta manera, se pueda contar con mejores insumos para poder ejercer un control social más efectivo, que permita reducir el riesgo de corrupción y mejore la confianza en las instituciones por parte de los ciudadanos. 


\section{Resultados del estudio}

El trabajo empírico se realizó sobre 30 de las 45 entidades objeto de estudio, ya que solo estas contaban con sitio web. La evaluación del grado de revelación de información se realizó con 61 indicadores que corresponden a los aspectos señalados en la metodología, cada uno con una puntuación máxima de 30 puntos. La indagación de los datos en los sitios web se efectuó durante marzo de 2013.
Los resultados obtenidos muestran el grado de revelación y divulgación por indicador y por aspecto. Así mismo, se elaboró un ranking por entidades de acuerdo con el grado de cumplimiento de lo establecido en la estrategia de gobierno en línea.

Debido a la gran cantidad de indicadores evaluados, los resultados se presentan teniendo como referencia tres categorías que corresponden al grado de revelación y divulgación de la información: mayor, parcial y menor. A continuación, se presentan los resultados.

\begin{tabular}{|c|c|c|}
\hline Indicadores & Puntaje & Aspecto \\
\hline $\begin{array}{l}\text { La entidad publica su información general y los canales de atención al } \\
\text { ciudadano en www.gobiernoenlinea.gov.co. }\end{array}$ & 30 & Información general \\
\hline $\begin{array}{l}\text { La entidad debe habilitar una sección que contenga las noticias más relevantes } \\
\text { para la entidad y que estén relacionadas con su actividad. }\end{array}$ & 30 & Información general \\
\hline $\begin{array}{l}\text { La entidad publica su localización física (ciudad y departamento, horarios y } \\
\text { días de atención al público, dirección y enlace a los datos de contacto de las } \\
\text { sucursales o regionales con las que cuente la entidad). }\end{array}$ & 29,5 & Información general \\
\hline La entidad publica su misión y visión. & 28,5 & Información general \\
\hline La entidad publica sus funciones y objetivos. & 28 & Información general \\
\hline $\begin{array}{l}\text { La entidad publica, de manera gráfica y legible, la estructura organizacional de } \\
\text { la entidad. }\end{array}$ & 28 & Información general \\
\hline $\begin{array}{l}\text { La entidad publica datos de contacto (teléfonos, líneas gratuitas, fax, correo } \\
\text { electrónico o enlace al sistema de atención al ciudadano, correo para } \\
\text { notificaciones judiciales). }\end{array}$ & 28 & Información general \\
\hline $\begin{array}{l}\text { La entidad debe tener un enlace que dirija las políticas de seguridad de la } \\
\text { información y protección de datos personales. }\end{array}$ & 28 & Información general \\
\hline $\begin{array}{l}\text { La entidad ofrece una lista de respuestas a preguntas frecuentes relacionadas } \\
\text { con la entidad, su gestión y los servicios y trámites que presta. }\end{array}$ & 28 & Información general \\
\hline $\begin{array}{l}\text { La entidad publica la normatividad que la rige, la que determina su } \\
\text { competencia y la que es aplicable a su actividad o producida por ella como } \\
\text { decretos; esta información debe ser descargable. }\end{array}$ & 27 & $\begin{array}{l}\text { Normatividad, política } \\
\text { y lineamientos }\end{array}$ \\
\hline $\begin{array}{l}\text { La entidad publica ofertas de empleos y prestación de servicios, con los } \\
\text { respectivos resultados de los procesos. Se debe actualizar cuando finalicen los } \\
\text { procesos de selección. }\end{array}$ & 27 & Recurso humano \\
\hline
\end{tabular}

Tabla 1. Indicadores con mayor grado de revelación y divulgación Fuente: elaboración propia, a partir del Manual de implementación de gobierno en línea (2012). 
Los indicadores con el mayor grado de divulgación, en suma, pertenecen al aspecto de información general y evidencian puntajes entre 28 y 30; esta última es la puntuación más alta que se podía obtener en el proceso de evaluación. En este sentido, las entidades procuran presentar la información que les permita a los ciudadanos conocer las noticias más relevantes de la entidad y tener acceso a la información general y canales de atención, lo cual resulta importante para posibilitar un primer acercamiento entre los usuarios y las instituciones.

De igual forma, la información relacionada con la prestación de los servicios y funciones de las entidades es revelada de manera amplia, asunto consistente con el propósito de la estrategia de gobierno en línea, al buscar una prestación rápida y oportuna de estos, para minimizar los trámites y la carga administrativa para llevar a cabo los procesos y procedimientos ante las entidades.

Por otra parte, se observó que si bien se establece una sección de ofertas de empleo, al ingresar a los enlaces correspondientes en la mayoría de las entidades, no hay ninguna información, lo que deja en duda el uso que se hace de este espacio o si el desarrollo de estos procesos se lleva a cabo por otros medios.

Entre los indicadores más divulgados no hay aspectos relacionados con información financiera, planeación, contratación, trámites y servicios, lo cual se considera debería publicarse de manera completa para que los ciudadanos indaguen sobre la administración de los recursos por parte de los gestores públicos. Esta situación se confirma al observar los indicadores parciales y menos publicados, como se muestra en las siguientes tablas:

\begin{tabular}{|c|c|c|}
\hline Indicador & Puntaje & Aspecto \\
\hline $\begin{array}{l}\text { La entidad publica los planes de mejoramiento vigentes y los planes de } \\
\text { mejoramiento, de acuerdo con los hallazgos de la Contraloría (año 2012). }\end{array}$ & 20 & $\begin{array}{l}\text { Planeación, gestión y } \\
\text { control }\end{array}$ \\
\hline $\begin{array}{l}\text { La entidad publica el informe pormenorizado del estado de control interno, } \\
\text { de acuerdo con lo señalado en el Estatuto anticorrupción o Ley } 1474 \text { de } \\
\text { 2011. Este informe debe ser publicado cada cuatro (4) meses (año 2012). }\end{array}$ & 19,5 & $\begin{array}{l}\text { Planeación, gestión y } \\
\text { control }\end{array}$ \\
\hline $\begin{array}{l}\text { La entidad publica la información detallada del presupuesto de ingresos y } \\
\text { gastos aprobado y ejecutado de dos años anteriores al año en ejercicio (año } \\
2010 \text { y 2011). }\end{array}$ & 18,5 & $\begin{array}{l}\text { Información financiera y } \\
\text { contable }\end{array}$ \\
\hline $\begin{array}{l}\text { La entidad publica los estados financieros con corte a } 31 \text { de diciembre de } \\
\text { las dos últimas vigencias (año } 2011 \text { y 2012). }\end{array}$ & 17 & $\begin{array}{l}\text { Información financiera y } \\
\text { contable }\end{array}$ \\
\hline $\begin{array}{l}\text { La entidad publica el informe enviado al Congreso del período vigente y del } \\
\text { inmediatamente anterior (año 2012-2011). }\end{array}$ & 17 & $\begin{array}{l}\text { Planeación, gestión y } \\
\text { control }\end{array}$ \\
\hline $\begin{array}{l}\text { La entidad publica el plan de acción en el cual se especifiquen los objetivos, } \\
\text { estrategias, proyectos, metas, responsables, planes generales de compras y } \\
\text { distribución presupuestal de sus proyectos de inversión. Debe publicar su } \\
\text { avance mínimo cada tres (3) meses (marzo, junio, septiembre de 2012). }\end{array}$ & 16,5 & $\begin{array}{l}\text { Planeación, gestión y } \\
\text { control }\end{array}$ \\
\hline $\begin{array}{l}\text { La entidad publica la información relacionada con metas, indicadores de } \\
\text { gestión y/o desempeño, de acuerdo con su planeación estratégica. Se debe } \\
\text { publicar su estado, mínimo cada tres (3) meses (marzo, junio, septiembre } \\
\text { de 2012). }\end{array}$ & 15,5 & $\begin{array}{l}\text { Planeación, gestión y } \\
\text { control }\end{array}$ \\
\hline
\end{tabular}




\begin{tabular}{lcl}
\hline \multicolumn{1}{c}{ Indicador } & Puntaje & \multicolumn{1}{c}{ Aspecto } \\
\hline $\begin{array}{l}\text { La entidad publica el presupuesto aprobado en ejercicio detallado (año } \\
\text { 2013). }\end{array}$ & 15 & $\begin{array}{l}\text { Información financiera y } \\
\text { contable }\end{array}$ \\
$\begin{array}{l}\text { La entidad ofrece información acerca de lineamientos, acciones y } \\
\text { resultados desarrollados en el marco de la responsabilidad social y en la } \\
\text { configuración de prácticas de buen gobierno. }\end{array}$ & 15 & Planeación, gestión y \\
La entidad publica el informe de rendición de cuentas a los ciudadanos, \\
$\begin{array}{l}\text { incluyendo la respuesta a las solicitudes realizadas por los ciudadanos, } \\
\text { antes y durante el ejercicio de rendición del período vigente y del }\end{array}$ \\
$\begin{array}{l}\text { inmediatamente anterior (año 2011 y 2012). } \\
\text { La entidad publica los estados financieros con corte a 31 de diciembre de } \\
\text { las últimas cinco vigencias (año 2008-2012). }\end{array}$
\end{tabular}

Tabla 2. Indicadores con un grado parcial de revelación y divulgación

Fuente: elaboración propia, a partir del Manual de implementación de gobierno en línea (2012).

La tabla 2 muestra los indicadores que obtuvieron un puntaje medio, dado que se presentan en los sitios web de algunas entidades o porque la información solicitada está incompleta. Estos indicadores se ubican entre 13 y 20 puntos; aunque no son resultados bajos, se debe tener en cuenta que el cumplimiento debe ser del $100 \%$ en todas las entidades.

Por lo anterior, la información relacionada con planes de mejoramiento e informes de control logra resultados notables, pero no da cuenta de un cumplimiento total en materia de publicación. A su vez, se debe reconocer que la divulgación de los informes de control interno ha cobrado mayor importancia en las instituciones por causa de los hechos de corrupción y, por ello, deben ser expuestos en su sitio web para posibilitar un mayor control, como se plantea en el Estatuto Anticorrupción. Al ser publicada, esta información permite a los ciudadanos reconocer el cumplimiento de los objetivos de la institución y verificar el uso eficiente, eficaz y económico de los recursos utilizados en el desarrollo de los procesos y actividades en la organización.
Por otra parte, se encuentra la información relacionada con estados financieros y presupuestos, cuyo resultado evidencia niveles medios de divulgación, lo cual impide la realización de un análisis financiero de la entidad que permita evaluar el desempeño de la administración.

Es de considerar que las entidades de la rama ejecutiva se rigen con base en las normas de contabilidad pública, que exigen la presentación de cuatro estados financieros (balance general; estado de actividad financiera, económica, social y ambiental; estado de cambios en el patrimonio y estado de flujos de efectivo), con sus notas respectivas. Si bien estos se deben publicar en el sistema Consolidador de Hacienda e Información Pública, CHIP, la estrategia de gobierno en línea establece que es-

2 Es un sistema de información que permite definir, capturar, consolidar y difundir información cuantitativa y cualitativa, producida por entidades públicas y otros proveedores de información, con destino al gobierno central, organismos de control y ciudadanía en general, para el apoyo en la toma de decisiones en materia de política macroeconómica, fiscal, así como la definición, ejecución y administración de planes de gobierno. 
tos deban ser exhibidos en sus sitios web, para posibilitar un mayor acceso a esa información. No obstante, se evidenció que ninguna entidad cumple plenamente los indicadores asociados a los estados financieros, en la medida en que no se cuenta con la información histórica requerida, falta el estado de flujos de efectivo y/o no se presentan las notas a los estados financieros.

En cuanto a la publicación de los presupuestos, se observa un problema de oportunidad de la información, ya que en las entidades se expone en mayor medida los presupuestos de los últimos años (2011 y 2012), con una nota de 18,5, que el presupuesto actual (15), lo cual explica los resultados parciales obtenidos.

Otra información relevante para analizar la gestión pública, corresponde a los planes de acción, los indicadores de gestión, el informe de rendición de cuentas a la ciudadanía y las acciones y resultados en materia de responsabilidad social, que está incompleto en su contenido, lo que limita el análisis con respecto a las metas y los indicadores que permiten medir el actuar del gobernante y considerar las explicaciones y/o justificaciones otorgadas por este de sus decisiones, para poder reconocer las actividades para mitigar los impactos sociales y ambientales que se pueden generar en el desarrollo de las actividades de la entidad.

Finalmente, se muestran los indicadores que con menor grado se revelan en los sitios web de las instituciones públicas, como se expone en la siguiente tabla.

\begin{tabular}{|c|c|c|}
\hline Indicadores & Puntaje & Aspecto \\
\hline $\begin{array}{l}\text { La entidad publica el informe de rendición de cuentas a los ciudadanos, incluyendo } \\
\text { la respuesta a las solicitudes realizadas por los ciudadanos, antes y durante el } \\
\text { ejercicio de rendición, de las últimas cinco vigencias (año 2008-2012). }\end{array}$ & 12,5 & $\begin{array}{l}\text { Planeación, gestión } \\
\text { y control }\end{array}$ \\
\hline $\begin{array}{l}\text { La entidad publica la información detallada del presupuesto de ingresos y gastos } \\
\text { aprobado y ejecutado de por lo menos el número de años del período presidencial } \\
\text { anterior y el actual (años 2006-2010). }\end{array}$ & 12,5 & $\begin{array}{l}\text { Información } \\
\text { financiera y contable }\end{array}$ \\
\hline $\begin{array}{l}\text { La entidad publica las notas a los Estados Financieros a } 31 \text { de diciembre de las } \\
\text { últimas cinco vigencias (año 2008-2012). }\end{array}$ & 11,5 & $\begin{array}{l}\text { Información } \\
\text { financiera y contable }\end{array}$ \\
\hline $\begin{array}{l}\text { La entidad debe publicar la ejecución del plan operativo anual de inversiones o del } \\
\text { instrumento en el que se consignen los proyectos de inversión o programas que se } \\
\text { ejecuten en cada vigencia mínimo cada tres (3) meses (marzo, junio, septiembre } \\
\text { de 2012). }\end{array}$ & 9 & $\begin{array}{l}\text { Planeación, gestión } \\
\text { y control }\end{array}$ \\
\hline $\begin{array}{l}\text { La entidad publica los resultados de la evaluación a funcionarios y el seguimiento a } \\
\text { los acuerdos de gestión de los funcionarios principales. }\end{array}$ & 9 & Recurso humano \\
\hline $\begin{array}{l}\text { La entidad publica otros planes relacionados con temas anticorrupción, rendición } \\
\text { de cuentas, servicio al ciudadano, antitrámites y los demás que la normatividad } \\
\text { vigente solicite. }\end{array}$ & 8,5 & $\begin{array}{l}\text { Planeación, gestión } \\
\text { y control }\end{array}$ \\
\hline $\begin{array}{l}\text { La entidad publica el informe de empalme del representante legal, cuando haya un } \\
\text { cambio de este y antes de desvincularse de la entidad. }\end{array}$ & 8 & $\begin{array}{l}\text { Planeación, gestión } \\
\text { y control }\end{array}$ \\
\hline $\begin{array}{l}\text { La entidad publica la tabla de retención documental y el programa de gestión } \\
\text { documental. }\end{array}$ & 7,5 & $\begin{array}{l}\text { Planeación, gestión } \\
\text { y control }\end{array}$ \\
\hline $\begin{array}{l}\text { La entidad publica el informe de rendición de la cuenta fiscal a la Contraloría } \\
\text { General de la República de las últimas cinco vigencias (año 2008-2012). }\end{array}$ & 6 & $\begin{array}{l}\text { Planeación, gestión } \\
\text { y control }\end{array}$ \\
\hline
\end{tabular}




\begin{tabular}{lcc}
\hline \multicolumn{1}{c}{ Indicadores } & Puntaje & Aspecto \\
\hline $\begin{array}{l}\text { La entidad publica trimestralmente un informe sobre las demandas a la entidad } \\
\text { (número de demandas, estado de cada una, pretensión o cuantía de la demanda, }\end{array}$ & 5 & Planeación, gestión \\
riesgo de pérdida) (año 2012). & y control \\
$\begin{array}{l}\text { La entidad publica el informe de rendición de la cuenta fiscal a la Contraloría } \\
\text { General de la República del período vigente y del inmediatamente anterior (año } \\
2011 \text { y 2012). }\end{array}$ & 4,5 & Planeación, gestión \\
\end{tabular}

Tabla 3. Indicadores con menor grado de revelación y divulgación Fuente: elaboración propia, a partir del Manual de implementación de gobierno en línea (2012).

Como se observa en la anterior tabla, el aspecto de planeación, gestión y control tiene el mayor número de indicadores que menos se divulgan. Este tipo de información corresponde con los informes de empalme del representante legal, rendición de cuentas, rendición de la cuenta fiscal, planes relacionados con anticorrupción y antitrámites, entre otros aspectos; conocer esta información es valioso, ya sea por entes reguladores o por los ciudadanos, por la gestión o control que cada uno de ellos realiza.

De manera particular, el indicador que menos se divulga es el informe de rendición de la cuenta fiscal a la Contraloría General de la República del período vigente y del inmediatamente anterior (año 2011 y 2012), que muestra las actuaciones legales, técnicas, contables, financieras y de gestión de la entidad. La Constitución Política, en el artículo 268, numeral segundo, establece que es atribución del Contralor General de la República: "revisar y fenecer las cuentas que deben llevar los responsables del erario y determinar el grado de eficiencia, eficacia y economía con que hayan obrado". Por esto es importante que se divulgue este tipo de informes para que los ciudadanos puedan conocer qué tan buena ha sido la gestión de los funcionarios, con respecto a los re- cursos de la Nación y al cumplimiento de las labores que les han sido encomendadas.

De igual forma, se limita la información relacionada con la publicación de los planes anticorrupción y antitrámites que han sido objeto de regulación y, por ende, de obligatorio cumplimiento, lo cual significa que las instituciones no han avanzado en esta materia y, por tanto, se debe trabajar en la configuración y exposición de esos planes, para que los ciudadanos puedan conocer sobre los objetivos, metas y controles planteados para prevenir prácticas no deseadas en la gestión.

Como resultado de los puntajes obtenidos en los indicadores, se obtiene el grado de revelación y divulgación de los aspectos propuestos en la estrategia de gobierno en línea, establecidos como requisitos mínimos en la fase de información.

La tabla 4 expone los valores mínimo y máximo obtenidos en las entidades evaluadas, es decir, la institución con el menor puntaje en la evaluación es la que soporta el valor mínimo y la mejor evaluada en el aspecto correspondiente es la que da cuenta del valor máximo. De igual forma, se muestra el promedio institucional, que corresponde a la nota promedio que se obtiene para cada aspecto en el conjunto de las entidades evaluadas. Con base en este promedio, se obtiene el grado de divulgación, que se expresa en términos porcentuales. 
REVELACIÓN ON-LINE DE LA INFORMACIÓN FINANCIERA Y NO FINANCIERA / H. MACÍAS, COMP. / 95

\begin{tabular}{lcccc}
\hline \multicolumn{1}{c}{ Aspecto } & $\begin{array}{c}\text { Valor } \\
\text { mínimo }\end{array}$ & $\begin{array}{c}\text { Valor } \\
\text { máximo }\end{array}$ & $\begin{array}{c}\text { Promedio } \\
\text { institucional }\end{array}$ & $\begin{array}{c}\text { Grado de } \\
\text { divulgación } \\
\text { (\%) }\end{array}$ \\
\hline Información general & 8,50 & 17,00 & 14,85 & 87,35 \\
Normatividad, política y lineamientos & 0,00 & 4,00 & 3,23 & 80,83 \\
Contratación & 0,00 & 3,00 & 2,23 & 74,44 \\
Recurso humano & 2,00 & 6,00 & 3,97 & 66,11 \\
Trámites y servicios & 0,00 & 2,00 & 1,32 & 65,83 \\
Planeación, gestión y control & 1,50 & 15,00 & 9,52 & 63,44 \\
Información financiera y contable & 0,00 & 6,00 & 3,73 & 62,22 \\
\hline
\end{tabular}

Tabla 4. Grado de revelación y divulgación por aspecto

Fuente: elaboración propia, a partir del Manual de implementación de gobierno en línea (2012).

Como se observa, los aspectos están organizados de mayor a menor grado de divulgación. El aspecto de Información general cuenta con el grado de divulgación más alto, siendo este de $87,35 \%$ y, el de información financiera y contable, el de menor grado con $62,22 \%$.

En este sentido, las entidades han cumplido en mayor medida al entregar la información concerniente a su funcionamiento y los servicios que ofrecen, lo que mejora el acercamiento con el ciudadano al entregarle datos con mayor rapidez, que le permiten conocer las características, requerimientos y formas de acceso a las instituciones públicas.

El aspecto de información financiera y contable, siendo uno de los más importantes para los usuarios en la toma de decisiones y control social, se muestra de una manera deficiente; esto lleva a que no se pueda indagar acerca de los hechos sucedidos en relación con la obtención y el uso de los recursos públicos en materia de inversiones, deudas y funcionamiento. Lo anterior limita la transparencia en la gestión del Estado, la evalua- ción que se pueda realizar sobre su eficiencia y la posibilidad de mitigar los riesgos de corrupción.

Estos resultados llevan a que el puntaje obtenido por cada institución no se acerque al máximo deseado (100\%), en revelación y divulgación de información, lo que coincide con investigaciones previas, como las desarrolladas por Vicente Pina, Lourdes Torres y Sonia Royo (2010), en administraciones públicas en Europa y, Alejandra Ríos y Guillermo Cejudo (2009) en las instituciones del poder ejecutivo en México.

El puntaje de cumplimiento promedio del grado de revelación y divulgación de información de las 30 instituciones evaluadas, es de $63,69 \%$, siendo este un nivel intermedio. Este resultado permite rechazar la hipótesis planteada para la presente investigación.

De forma particular, se obtuvo que de las 30 entidades evaluadas, 11 presentaron un nivel bajo, ya que no superaron el 60\% de cumplimiento, mientras que las 19 restantes evidencian mejores resultados. 


\begin{tabular}{|c|c|c|}
\hline Entidades & $\begin{array}{l}\text { Puntaje } \\
\text { obtenido }\end{array}$ & $\begin{array}{c}\text { Cumplimiento } \\
(\%)\end{array}$ \\
\hline Ministerio de Salud y de la Protección Social & 48,5 & 79,51 \\
\hline Departamento Administrativo de la Función Pública & 48,0 & 78,69 \\
\hline Presidencia de la República & 47,0 & 77,05 \\
\hline Departamento Administrativo Nacional de Estadística & 46,5 & 76,23 \\
\hline Ministerio de las Tecnologías de la Información y de las Comunicaciones & 46,5 & 76,23 \\
\hline Ministerio de Relaciones Exteriores & 46,0 & 75,41 \\
\hline Ministerio de Minas y Energía & 44,5 & 72,95 \\
\hline Comisión de Regulación de Energía y Gas & 44,0 & 72,13 \\
\hline Departamento Nacional de Planeación & 43,5 & 71,31 \\
\hline Ministerio de Agricultura y Desarrollo Rural & 43,0 & 70,49 \\
\hline Superintendencia de Puertos y Transportes & 42,5 & 69,67 \\
\hline Ministerio de Defensa Nacional & 42,5 & 69,67 \\
\hline Ministerio de Justicia y del Derecho & 41,5 & 68,03 \\
\hline Parques Nacionales Naturales de Colombia & 40,5 & 66,39 \\
\hline Ministerio de Ambiente y Desarrollo Sostenible & 40,0 & 65,57 \\
\hline Ministerio de Comercio, Industria y Turismo & 40,0 & 65,57 \\
\hline Ministerio de Educación Nacional & 39,5 & 64,75 \\
\hline Ministerio de Cultura & 39,0 & 63,93 \\
\hline Autoridad Nacional de Licencias Ambientales & 38,5 & 63,11 \\
\hline Ministerio de Vivienda, Ciudad y Territorio & 36,0 & 59,02 \\
\hline Ministerio de Trabajo & 35,0 & 57,38 \\
\hline Ministerio de Transporte & 35,0 & 57,38 \\
\hline Comisión de Regulación de Agua Potable y Saneamiento Básico & 34,5 & 56,56 \\
\hline Ministerio de Hacienda y Crédito Publico & 34,5 & 56,56 \\
\hline Ministerio del Interior & 34,0 & 55,74 \\
\hline \multicolumn{3}{|l|}{ Departamento Administrativo del Deporte, la Recreación, la Actividad Física y } \\
\hline el Aprovechamiento del Tiempo Libre & 34,0 & 55,74 \\
\hline Comisión de Regulación de Comunicaciones & 32,0 & 52,46 \\
\hline Departamento Administrativo de Ciencia, Tecnología e Innovación & 30,0 & 49,18 \\
\hline Departamento Administrativo para la Prosperidad Social & 25,0 & 40,98 \\
\hline Vicepresidencia de la República & 14,0 & 22,95 \\
\hline
\end{tabular}

Tabla 5. Ranking de entidades de la rama ejecutiva del orden nacional nivel central que cuentan con sitio web Fuente: elaboración propia 
La entidad con el mejor puntaje fue el Ministerio de Salud y de la Protección Social $(48,5)$, que alcanzó 79,51\% de cumplimiento de la información mínima a publicar en su sitio web. Esta entidad cumplió el 100\% del aspecto de información general; el 100\% en recurso humano; el 75\% en normatividad, políticas y lineamientos; el 83\% en el aspecto de contratación; el 66\% en planeación, gestión y control; el 64\% en información financiera y contable; y el 50\% en trámites y servicios; aunque ocupe el primer lugar, le hace falta mejorar aspectos como el de información financiera y el de trámites y servicios.

Por último, la entidad que menos divulga en su sitio web es la Vicepresidencia de la República, ya que obtuvo un puntaje de 14 sobre 61, es decir, tan solo cumple con el 22,95\%. Según lo observado, esta nota se debe a su dependencia de la Presidencia de la República, pues tiene enlazada gran parte de la información con el sitio web de esta y, cuando se accede a la información, esta solo hace referencia a la Presidencia.

\section{Conclusiones}

En 1991, Colombia asumió la forma de gobierno de Estado Social de Derecho, Democrático y Participativo, en la que prevalece el interés general de toda la ciudadanía y se facilita la participación de todos en las decisiones que los afecten. Lo anterior implica que en el contexto de los derechos y deberes, los ciudadanos pueden participar en los asuntos políticos y administrativos del Estado, con el fin de verificar el buen uso de los recursos destinados a la Nación para el bienestar común. Para que ese proceso de control social sea efectivo, los ciudadanos pueden entrar a cuestionar la actuación de los gestores públicos por distintos mecanismos, como la rendición de cuentas, que se entiende como la obligación de un actor de informar y explicar sus acciones a otro(s) que tienen el derecho de exigirla.

Con el propósito de evidenciar la efectividad en la rendición de cuentas en las instituciones públicas colombianas, la presente investigación evaluó el grado de revelación y divulgación de la información de las entidades que componen la rama ejecutiva del orden nacional nivel central, siguiendo los lineamientos previstos en la estrategia de gobierno en línea.

En su conjunto, los aspectos evaluados constituyen un insumo para que se llegue a realizar un control completo de las actuaciones de los gestores públicos y, por tal razón, se requiere que estén disponibles mediante el uso de las tecnologías de la información, como internet, con el fin de indagar sobre cualquier información que compete a la entidad y que sea de interés para cualquier tipo de usuario en cualquier tiempo y espacio.

Como resultado, se obtuvo que este tipo de instituciones muestra un grado intermedio de revelación y divulgación de la información financiera y no financiera, pues el aspecto que más publica es el de información general, lo que posibilita el cumplimiento de uno de los propósitos de la estrategia de gobierno en línea: la prestación eficiente de los servicios que están a cargo de la administración pública.

De igual forma, el aspecto menos revelado es el referido a la información financiera y contable. Este resultado constituye un riesgo de 
corrupción, pues para cualquier tipo de entidad la información financiera y contable es uno de los aspectos fundamentales en sus procesos económicos y administrativos, ya que ayuda a la toma de decisiones y al control de los recursos.

Por último, con los resultados obtenidos se advierte la necesidad de aplicar y mejorar los controles por parte de los entes reguladores y fiscalizadores, con el fin de garantizar el cumplimiento de la estrategia de gobierno en línea $y$, por ende, lograr mejores procesos de rendición de cuentas que permitan un mayor acercamiento e interacción entre los gobiernos y sus gobernados, ya que es importante recordar que la información es la base de toda sociedad democrática.

\section{Referencias}

Arboleda, Germán (2008). Evaluación de políticas públicas. Cali: AC Editores.

Arias-Aguirre, Beatriz Elena \& Vélez-Tobón, Ramiro (2010). El control social como elemento fundamental en el ejercicio de la democracia participativa. Lecciones de Gobierno, 1 (1), 1518. Disponible en: http://www.udem.edu.co/ images/SERVICIOS/SelloEditorial/Lecciones_de_Gobierno/Articulo_2.pdf

Católico, Diego Fernando (2012). Revelación y divulgación de la información financiera y no financiera de las universidad públicas en Colombia. Revista Facultad de Ciencias Económicas: Investigación y Reflexión, XX (1), 57-76. Disponible en: http://www.redalyc. org/articulo.oa?id=90924279005

Colombia (1991). Constitución Política de Colombia. Bogotá, D.C. Disponible en: http:// www.alcaldiabogota.gov.co/sisjur/normas/ Norma1.jsp?i=4125

Colombia (2008). Decreto 1151 de 2008, por el cual se establecen los lineamientos generales de la estrategia de gobierno en línea de la República de Colombia, se reglamenta parcialmente la Ley 962 de 2005 y se dictan otras disposiciones. Diario Oficial, 46.960, 14 de abril de 2008. Disponible en: http:// www.alcaldiabogota.gov.co/sisjur/normas/ Norma1.jsp?i=29774

Colombia (2012). Decreto 2693 de 2012, por el cual se establecen los lineamientos generales de la estrategia de gobierno en línea de la República de Colombia, se reglamentan parcialmente las Leyes $1341 \mathrm{de}$ 2009 y 1450 de 2011 y se dictan otras disposiciones. Diario Oficial, 48.651, 21 de diciembre de 2012. Disponible en: http:// www.alcaldiabogota.gov.co/sisjur/normas/ Norma1.jsp?i $=51198$

Colombia (1998). Ley 489 de 1998, por la cual se dictan normas sobre la organización y funcionamiento de las entidades del orden nacional, se expiden las disposiciones, principios y reglas generales para el ejercicio de las atribuciones previstas en los numerales 15 y 16 del artículo 189 de la Constitución Política y se dictan otras disposiciones. Diario Oficial, 43.464, 30 de diciembre de 1998. Disponible en: http://www.alcaldiabogota. gov.co/sisjur/normas/Norma1.jsp?i=186

Colombia (2011). Ley 1474 de 2011 o Estatuto Anticorrupción, por la cual se dictan normas orientadas a fortalecer los mecanismos de prevención, investigación y sanción de actos de corrupción y la efectividad del 
control de la gestión pública. Diario Oficial, 48.128, 12 de julio de 2011. Disponible en: http://www.colciencias.gov.co/normatividad/ley-1474-de-2011

Consejo Nacional de Política Económica y Social, CONPES (2010). Documento 3650. Importancia estratégica de la estrategia de gobierno en línea. Bogotá D.C.: Departamento Nacional de Planeación. Disponible en: https://www.dnp.gov.co/LinkClick.as px?fileticket $=g B 3 p Q J G 1 R \% 2 f \circ \% 3 d \& t a b$ id $=1063$

Consejo Nacional de Política Económica y Social, CONPES (2010). Documento 3654. Política de rendición de cuentas de la rama ejecutiva a los ciudadanos. Bogotá D.C.: Departamento Nacional de Planeación. Disponible en: http://www.ani.gov.co/sites/ default/files/documento_conpes_3654_rendicion_de_cuentas.pdf

Corte Constitucional de Colombia (2002). Sentencia T-596 de 2002, participación ciudadana, alcance; participación ciudadana, derecho deber; democracia participativa y democracia representativa, veedurías ciudadanas; normas específicas constitucionales. Magistrado ponente: Manuel José Cepeda-Espinosa. Disponible en: http://www.corteconstitucional.gov.co/ relatoria/2002/T-596-02.htm

Cunill-Grau, Nuria (2007). La rendición de cuentas y el control social. Una aproximación conceptual. Disponible en: https:// www.dnp.gov.co/Portals/0/archivos/documentos/DDTS/Gestion_Publica_Territorial/RC_Nuria\%20Cunill\%20Grau.pdf
Departamento Administrativo de la Función Pública, DAFP (2011). Hacia una cultura de rendición de cuentas a la ciudadanía. Manual práctico para la Administración Pública. Bogotá D.C. Disponible en: http://portal. dafp.gov.co/form/formularios.retrive publicaciones?no $=1066$

Departamento Nacional de Planeación, DNP; Dirección de Evaluación de Políticas Públicas, DEPP; Departamento Administrativo de la Función Pública, DAFF; Contraloría General de la República; OCASA; Corporación Transparencia por Colombia; Deutsche Gesellschaft für Technische Zusammenarbeit (Cooperación Técnica Alemana), GTZ (2008). Cartilla para tejer una rendición de cuentas que cuente con la gente. Bogotá D.C. Disponible en: http://www.transparenciacolombia.org.co/index.php?option=com_co ntent\&view $=$ article\&id $=227$ : cartilla-paratejer-una-rendicion-de-cuentas-que-cuentecon-la-gente\&Itemid $=479$

Farfán, Mabel \& Gordillo, Andrés F. (2004). La participación ciudadana en Colombia. En Identidades sociales, 9. Bogotá: Grupo Editorial Norma.

Gómez, Fabio \& Católico, Diego Fernando (2009). Revelación y divulgación de la información financiera y no financiera on-line de las 500 empresas más representativas en Colombia. Revista Cuadernos de Contabilidad, 10 (27), 269-318. Disponible en: http://www.javeriana.edu.co/fcea/cuadernos_contab/vol10_n_27/vol10_27_3.pdf Grant, Ruth W \& Keohane, Robert O. (2005). Accountability and Abuses of Power in World Politics. American Political Science 
Review, 99 (1), 29-43. Disponible en: http:// www.princeton.edu/ rkeohane/publications/apsr_abuses.pdf

Ministerio de Tecnologías de la Información y las Comunicaciones, MinTIC (2011). Manual 3.0, para la implementacion de la estrategia de gobierno en línea de la República de Colombia. Bogotá D.C. Disponible en: http://www.expresate.com.co/contenido/ gel/manual-3.0.html

Ministerio de Tecnologías de la Información y las Comunicaciones, MinTIC (2012). Manual 3.1 para la implementación de la Estrategia de Gobierno en línea en las entidades del orden nacional de la República de Colombia. Bogotá D.C. Disponible en: http://www.minjusticia.gov.co/Portals/0/ Ministerio/Planeacion_gestion_y_control/ informe_de_GEL/Informe_de_Gobierno_ en_L\%C3\%ADnea_2013_-_OIJ_ver_web. pdf

Ministerio de Tecnologías de la Información y las Comunicaciones, MinTIC (2010). El Gobierno en Línea en Colombia 2009. Bogotá D.C. Disponible en: http://programa. gobiernoenlinea.gov.co/apc-aa-files/5854 534aee4eee4102f0bd5ca294791f/El_Gobierno_en_linea_en_Colombia_2009.pdf, http://programa.gobiernoenlinea.gov.co/ apc-aa-files/5854534aee4eee4102f0bd5c a294791f/GEL_PresentacionPlandeAcci_ n2009_20090325.ppt

Morón, Juan Carlos (2000). Los deberes de transparencia (accountability) en la gestión pública (con principal énfasis en sus indicadores para la gestión municipal). Revista Probidad, 8 (en línea), Perú. Disponible en: http://www.revistaprobidad.info/008/art03. html

Nohlen, Dieter (1984). Elecciones y sistemas electorales. Bonn: Fundación Friedrich Ebert.

Pina, Vicente; Torres, Lourdes \& Royo, Sonia (2010). Is E-Government Promoting Convergence Towards More Accountable Local Governments? International Public Management Journal, 13 (4), 350-380.

Presidencia de la República de Colombia (2000). Directiva Presidencial 02. Gobierno en Línea. Bogotá D.C.

Przeworski, Adam (1998). Democracia y representación. Revista del CLAD Reforma y Democracia, 10, 7-32. Disponible en: http:// unpan1.un.org/intradoc/groups/public/documents/CLAD/CLAD0030103.pdf

Riascos, Sandra Cristina; Martínez-Giordano, Graciela \& Solano, Ómar Javier (2008). El Gobierno Electrónico como estrategia de participación ciudadana en la Administración pública a nivel de Sudamérica - Casos Colombia y Uruguay. CollECTer Iberoamérica (en línea). Disponible en: http://gyepro. univalle.edu.co/documentos/linc1.pdf

Ríos, Alejandra \& Cejudo, Guillermo (2009). La rendición de cuentas de los gobiernos estatales en México. En Mauricio Merino, Sergio López \& Guillermo Cejudo (coord.). La estructura de la rendición de cuentas en México, 115-204. México D.F.: Universidad Autónoma de México.

Rivero, José Ángel; Mora-Agudo, Leonor \& Flores-Ureba, Sandra (2007). Un estudio de la rendición de cuentas a través del egobierno en la administración local espa- 
REVELACIÓN ON-LINE DE LA INFORMACIÓN FINANCIERA Y NO FINANCIERA / H. MACÍAS, COMP. / 101

ñola. En Empresa global y mercados locales. XXI Congreso Anual AEDEM, Universidad Rey Juan Carlos, Madrid, 6, 7 y 8 de junio de 2007. Madrid: Escuela Superior de Gestión Comercial y Marketing, ESIC. Disponible en: http://dialnet.unirioja.es/servlet/ libro?codigo=275423, file://D:/Mis\%20 documentos/Downloads/Dialnet-UnEstudioDeLaRendicionDeCuentasATravesDelEgobierno-2521491.pdf

Rodríguez-Bolívar, Manuel Pedro; López-Hernández, Antonio Manuel \& Caba-Pérez, María del Carmen (2005). La divulgación de información financiera gubernamental en Internet. Un estudio comparativo de los países sudamericanos y continentales europeos. Actas conferencia IADIS Ibero-Americana WWW/Internet 2005. Editorial IADIS Press.

Royo, Sonia (2008). El gobierno electrónico en la rendición de cuentas de la administración local. Revista Española de Financiación y Contabilidad, 137, 175-178. Disponible en: http://www.aeca.es/pub/refc/prestesis/ Royo_2008_REFC.pdf

Schedler, Andreas (2004). ¿Qué es la rendición de cuentas? Cuadernos de Transparencia, 3. México: Instituto Federal de Acceso a la Información y Protección de Datos, IFAI. Versión original en Andreas Schedler, La- rry Diamond y Marc F. Plattner (1999). The Self-Restraining State: Power and Accountability in New Democracies, 13-28. Lynne Rienner Publishers. Disponible en http:// works.bepress.com/cgi/viewcontent.cgi?arti $\mathrm{cle}=1005 \&$ context $=$ andreas_schedler\&seiredir $=1 \&$ referer $=$ http $\% 3 \mathrm{~A} \% 2 \mathrm{~F} \% 2 \mathrm{Fwww}$. bing.com\%2Fsearch\%3Fsetmkt\%3DesES\%26q\%3DSchedler\%252C\%2BA.\% 2B\%282004\%29.\%2B\%25C2\%25BFQ u\%25C3\%25A9\%2Bes\%2Bla\%2Brend ici\%25C3\%25B3n\%2Bde\%2Bcuentas $\% 253 \mathrm{~F} \#$ search $=\% 22$ Schedler $\% 2 \mathrm{C} \% 20$

A.\%20\%282004\%29.\%20

\%C2\%BFQu\%C3\%A9\%20es\%20

la\%20rendici\%C3\%B3n\%20de\%20 cuentas $\% 3 \mathrm{~F} \% 22$

- Fecha de recepción: 6 de junio de 2013

- Fecha de aceptación: 3 de febrero de 2014

\section{Para citar este artículo}

Católico-Segura, Diego Fernando; GómezSolano, Paola Andrea \& Gómez-Díaz, Angy Johana (2014). Revelación on-line de la información financiera y no financiera de las entidades de la rama ejecutiva del orden nacional en Colombia. Cuadernos de Contabilidad, 15 (37), 77-107. 


\section{Anexos}

\section{Anexo 1: Rama ejecutiva del orden nacional del nivel central}

\begin{tabular}{|c|c|}
\hline & Sitio web \\
\hline Presidencia de la República & www.presidencia.gov.co/ \\
\hline Vicepresidencia de la República & www.vicepresidencia.gov.co/ \\
\hline \multicolumn{2}{|l|}{ Ministerios } \\
\hline Ministerio del Interior & www.mininterior.gov.co/ \\
\hline Ministerio de Relaciones Exteriores & www.cancilleria.gov.co \\
\hline Ministerio de Hacienda y Crédito Público & www.minhacienda.gov.co/ \\
\hline Ministerio de Justicia y del Derecho & www.minjusticia.gov.co/ \\
\hline Ministerio de Defensa Nacional & www.mindefensa.gov.co/ \\
\hline Ministerio de Agricultura y Desarrollo Rural & www.minagricultura.gov.co \\
\hline Ministerio de Salud y de la Protección Social & www.minsalud.gov.co/ \\
\hline Ministerio de Trabajo & www.mintrabajo.gov.co \\
\hline Ministerio de Minas y Energía & www.minminas.gov.co/ \\
\hline Ministerio de Comercio, Industria y Turismo & www.mincomercio.gov.co/ \\
\hline Ministerio de Educación Nacional & www.mineducacion.gov.co/ \\
\hline Ministerio de Ambiente y Desarrollo Sostenible & www.minambiente.gov.co \\
\hline Ministerio de Vivienda, Ciudad y Territorio & www.minvivienda.gov.co/ \\
\hline Ministerio de Tecnologías de la Información y de las Comunicaciones & www.mintic.gov.co \\
\hline Ministerio de Transporte & www.mintransporte.gov.co/ \\
\hline Ministerio de Cultura & www.mincultura.gov.co \\
\hline
\end{tabular}

\section{Departamentos administrativos}

Departamento Administrativo de Ciencia, Tecnología e Innovación

Departamento Administrativo de la Función Pública

www.colciencias.gov.co/

Departamento Administrativo de la Presidencia de la República

www.dafp.gov.co

Departamento Administrativo del Deporte, la Recreación, la Actividad física y el

No cuenta con sitio web

Aprovechamiento del Tiempo Libre

www.coldeportes.gov.co

Departamento Administrativo Nacional de Estadística

www.dane.gov.co/

Departamento Administrativo para la Prosperidad Social

www.accionsocial.gov.co

Departamento Nacional de Planeación

www.dnp.gov.co/

Dirección Nacional de Inteligencia

No cuenta con sitio web

\section{Superintendencias}

Superintendencia de Puertos y Transportes www.supertransporte.gov.co/

\section{Unidades administrativas especiales}

Agencia del Inspector General de Tributos, Rentas y Contribuciones Parafiscales

No cuenta con sitio web 


\section{REVELACIÓN ON-LINE DE LA INFORMACIÓN FINANCIERA Y NO FINANCIERA / H. MACÍAS, comp. / 103}

\begin{tabular}{|c|c|}
\hline & Sitio web \\
\hline Comisión de Regulación de Agua Potable y Saneamiento Básico & www.cra.gov.co \\
\hline Comisión de Regulación de Comunicaciones & www.crcom.gov.co/ \\
\hline Comisión de Regulación de Energía y Gas & www.creg.gov.co \\
\hline Parques Nacionales Naturales de Colombia & www.parquesnacionales.gov.co/ \\
\hline \multicolumn{2}{|l|}{ Unidad de Planificación de Tierras Rurales, Adecuación de Tierras y Usos } \\
\hline Agropecuarios & No cuenta con sitio Web \\
\hline Unidad de Proyección Normativa y Estudios de Regulación Financiera & No cuenta con sitio Web \\
\hline \multicolumn{2}{|l|}{ Consejos superiores } \\
\hline Consejo Superior de Seguridad y Defensa Nacional & No cuenta con sitio Web \\
\hline Consejo Superior de Comercio Exterior & No cuenta con sitio Web \\
\hline Consejo Superior de Política Fiscal - CONFIS & No cuenta con sitio Web \\
\hline Consejo Superior de Empleo, Trabajo y Seguridad Social & No cuenta con sitio Web \\
\hline Consejo Superior del Subsidio Familiar & No cuenta con sitio Web \\
\hline Consejo Superior de Empleo, Trabajo y Seguridad Social & No cuenta con sitio Web \\
\hline Consejo Superior del Subsidio Familiar & No cuenta con sitio Web \\
\hline Consejo Superior de Comercio Exterior & No cuenta con sitio Web \\
\hline Consejo Superior de Microempresa & No cuenta con sitio Web \\
\hline Consejo Superior de Pequeña y Mediana Empresa & No cuenta con sitio Web \\
\hline
\end{tabular}

\section{Anexo 2: Indicadores trabajados}

\begin{tabular}{lc}
\hline \multicolumn{1}{c}{ Información general } & \multicolumn{1}{c}{ Tipo de } \\
\hline \multicolumn{1}{c}{ Indicadores } & evaluación \\
\hline $\begin{array}{l}\text { La entidad publica su información general y los canales de atención al ciudadano en www. } \\
\text { gobiernoenlinea.gov.co }\end{array}$ & $0-1$ \\
La entidad publica su misión y visión. & $0-0,5-1$ \\
La entidad publica sus funciones y objetivos. & $0-0,5-1$ \\
La entidad publica, de manera gráfica y legible, la estructura organizacional de la entidad. \\
$\begin{array}{l}\text { La entidad publica la lista de entidades que integran el mismo sector-rama-organismo, con enlace } \\
\text { al sitio web de cada una de estas. }\end{array}$ & $0-0,5-1$ \\
La entidad publica la lista de las principales agremiaciones o asociaciones relacionadas con la \\
$\begin{array}{l}\text { actividad propia de la entidad, con enlace al sitio web de cada una de estas. } \\
\text { La entidad publica datos de contacto (teléfonos, líneas gratuitas, fax, correo electrónico o enlace al } \\
\text { sistema de atención al ciudadano, correo para notificaciones judiciales). }\end{array}$ \\
$\begin{array}{l}\text { La entidad publica su localización física (ciudad y departamento, horarios y días de atención al } \\
\text { público, dirección y enlace a los datos de contacto de las sucursales o regionales con las que cuente } \\
\text { la entidad). }\end{array}$ \\
$\begin{array}{l}\text { La entidad debe tener un enlace de los datos de contacto de la planta de personal de la entidad. } \\
\text { La entidad debe tener un enlace que dirija las políticas de seguridad de la información y protección } \\
\text { de datos personales. }\end{array}$ \\
\hline
\end{tabular}




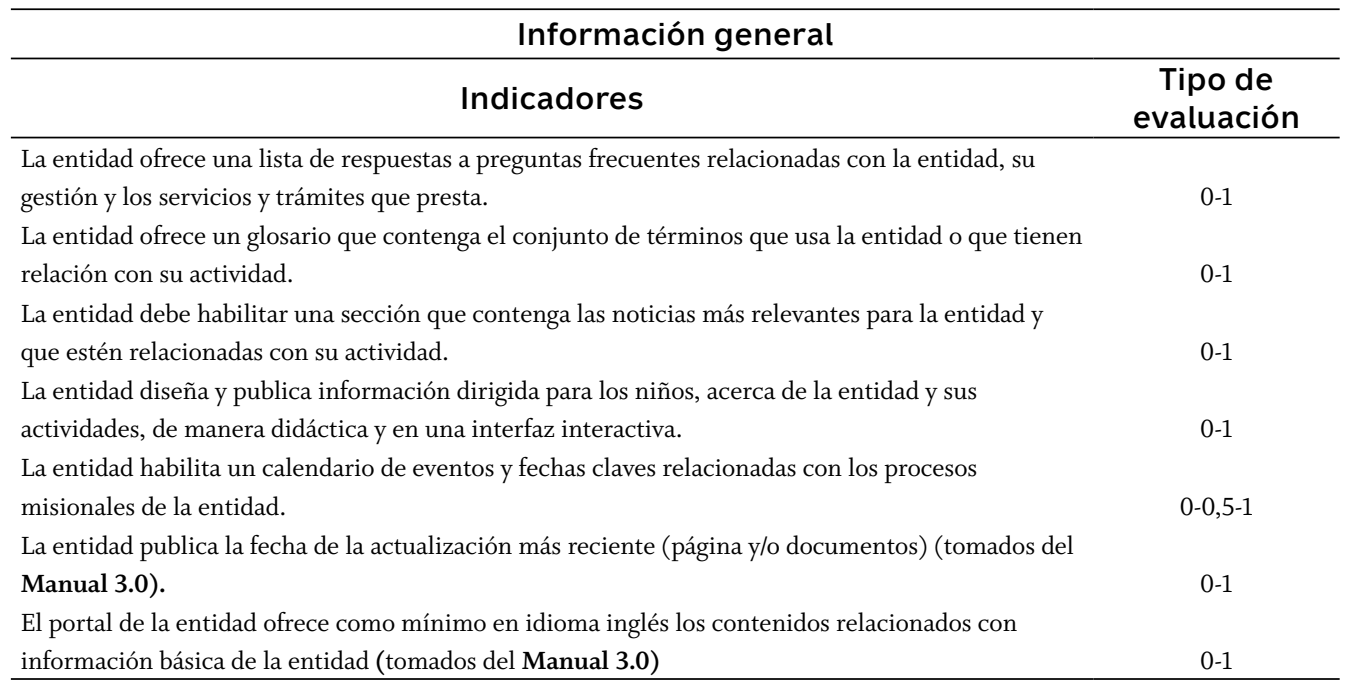

\section{Normatividad, política y lineamientos} Indicadores

La entidad publica la normatividad que la rige, la que determina su competencia y la que es aplicable a su actividad o producida por ella como leyes, ordenanzas, acuerdos; esta información debe ser descargable.

La entidad publica la normatividad que la rige, la que determina su competencia y la que es aplicable a su actividad o producida por ella como decretos; esta información debe ser descargable. La entidad publica la normatividad que la rige, la que determina su competencia y la que es aplicable a su actividad o producida por ella como resoluciones, circulares y/u otros actos administrativos de carácter general; esta información debe ser descargable. La entidad publica la normatividad que la rige, la que determina su competencia y la que es aplicable a su actividad o producida por ella como políticas, lineamientos y manuales; esta información debe ser descargable.

\section{Información financiera y contable}

\section{Indicadores}

La entidad publica el presupuesto aprobado en ejercicio detallado (año 2013).

La entidad publica el presupuesto ejecutado mínimo cada tres meses (marzo, junio, septiembre 2012).

La entidad publica la información detallada del presupuesto de ingresos y gastos aprobado y ejecutado de los dos años anteriores al año en ejercicio (año 2010 y 2011).

La entidad publica la información detallada del presupuesto de ingresos y gastos aprobado y ejecutado de por lo menos el número de años del período presidencial anterior y actual (años 20062010).

La entidad publica los estados financieros con corte a 31 de diciembre de las dos últimas vigencias (año 2011 y 2012).

\section{Tipo de evaluación}




\section{REVELACIÓN ON-LINE DE LA INFORMACIÓN FINANCIERA Y NO FINANCIERA / H. MACÍAS, cOMP. / 105}

\begin{tabular}{lc}
\hline \multicolumn{1}{c}{ Información financiera y contable } \\
\hline \multicolumn{1}{c}{ Indicadores } & $\begin{array}{c}\text { Tipo de } \\
\text { evaluación }\end{array}$ \\
\hline $\begin{array}{l}\text { La entidad publica los estados financieros con corte a 31 de diciembre de las últimas cinco vigencias } \\
\text { (año 2008-2012). }\end{array}$ & $0-0,5-1$ \\
$\begin{array}{l}\text { La entidad publica las notas a los Estados Financieros a 31 de diciembre de las últimas cinco } \\
\text { vigencias (año 2008-2012). }\end{array}$ & $0-0,5-1$ \\
\hline
\end{tabular}

\begin{tabular}{lc}
\hline Planeación, gestión y control & Tipo de \\
\hline Indicadores & evaluación \\
\hline
\end{tabular}

La entidad publica sus políticas, planes o líneas estratégicas y como mínimo su plan estratégico vigente (año 2013).

$0-0,5-1$

La entidad publica sus políticas, planes o líneas estratégicas llevadas a cabo durante la anterior y actual legislaturas presidenciales (año 2008-2012).

La entidad publica el plan de acción en el que se especifican los objetivos, estrategias, proyectos, metas, responsables, planes generales de compras y la distribución presupuestal de sus proyectos de inversión de la vigencia actual (año 2013).

La entidad publica el plan de acción en el que se especifican los objetivos, estrategias, proyectos, metas, responsables, planes generales de compras y la distribución presupuestal de sus proyectos de inversión. Debe publicar su avance mínimo cada tres (3) meses (marzo, junio, septiembre de 2012). La entidad debe publicar como mínimo el plan operativo anual de inversiones o el instrumento en el que se consignen los proyectos de inversión o programas que se ejecuten en cada vigencia (año 2013).

La entidad debe publicar la ejecución del plan operativo anual de inversiones o del instrumento en el que se consignen los proyectos de inversión o programas que se ejecuten en cada vigencia mínimo cada tres (3) meses (marzo, junio, septiembre de 2012).

La entidad publica la relación de todas las entidades que la vigilan y los mecanismos de control que hay dentro y fuera para hacer un seguimiento efectivo sobre su gestión.

La entidad publica el informe enviado al Congreso del período vigente y del inmediatamente anterior (año 2012-2011).

La entidad publica el informe de rendición de la cuenta fiscal a la Contraloría General de la República del período vigente y del inmediatamente anterior (año 2011 y 2012).

La entidad publica el informe de rendición de la cuenta fiscal a la Contraloría General de la

República de las últimas cinco vigencias (año 2008-2012).

La entidad publica el informe de rendición de cuentas a los ciudadanos, incluyendo la respuesta a las solicitudes realizadas por los ciudadanos, antes y durante el ejercicio de rendición del período vigente y del inmediatamente anterior (año 2011 y 2012).

La entidad publica el informe de rendición de cuentas a los ciudadanos incluyendo la respuesta a las solicitudes realizadas por los ciudadanos, antes y durante el ejercicio de rendición, de las últimas cinco vigencias (año 2008-2012).

La entidad publica la información relacionada con metas, indicadores de gestión y/o desempeño, de acuerdo con su planeación estratégica. Se debe publicar su estado, mínimo cada tres (3) meses (marzo, junio, septiembre de 2012).

La entidad publica los planes de mejoramiento vigentes y los planes de mejoramiento de acuerdo con los hallazgos de la Contraloría (año 2012). 


\section{Planeación, gestión y control}

\section{Indicadores}

La entidad publica el informe pormenorizado del estado de control interno de acuerdo con lo señalado en el estatuto anticorrupción. Este informe debe ser publicado cada cuatro (4) meses (año

$0-0,5-1$ 2012).

La entidad publica el informe de empalme del representante legal, cuando haya un cambio del mismo y antes de desvincularse de la entidad.

La entidad publica las normas, la política, los programas y los proyectos dirigidos a población vulnerable de acuerdo con su misión.

La entidad publica la lista de beneficiarios de los programas sociales de la población vulnerable.

La entidad ofrece información acerca de lineamientos, acciones y resultados desarrollados en el marco de la responsabilidad social y en la configuración de prácticas de buen gobierno.

La entidad publica trimestralmente un informe sobre las demandas a la entidad (número de demandas, estado en que se encuentra, pretensión o cuantía de la demanda, riesgo de pérdida) (año 2012).

La entidad publica la tabla de retención documental y el programa de gestión documental.

$0-0,5-1$

\section{Contratación}

\section{Indicadores}

Tipo de evaluación

La entidad publica el plan de compras de la vigencia respectiva. Se debe publicar su ejecución, de acuerdo con la periodicidad de los reportes que establezca Colombia Compra Eficiente (año 2013). La entidad debe publicar en el Sistema Electrónico de Contratación Pública, SECOP (portal único de contratación) todos sus procesos de contratación, se debe generar un enlace que direccione la información publicada por la entidad en el SECOP en la página de inicio del sitio web de la entidad. La entidad publica todos sus procesos de contratación en su sitio web (términos de referencia, licitación, contratos, actas de liquidación e informes de seguimiento).

\section{Trámites y servicios}

\section{Indicadores}

La entidad publica en un lugar plenamente visible de la página inicial un enlace a la sección de trámites y servicios, en la que proporcione una lista con el nombre de cada trámite o servicio, enlazado a la información sobre este en el Portal del Estado Colombiano (PEC).

La entidad publica semestralmente un informe de todas las peticiones recibidas y los tiempos de respuesta relacionados, junto con un análisis resumido de este mismo tema.

\section{Recurso humano}

\section{Indicadores}

La entidad publica el manual de funciones y competencias; adicionalmente cada vez que se cambian o ajustan. 
REVELACIÓN ON-LINE DE LA INFORMACIÓN FINANCIERA Y NO FINANCIERA / H. MACÍAS, COMP. / 107

\section{Recurso humano}

\section{Indicadores}

Tipo de evaluación

La entidad publica la escala salarial correspondiente a las categorías de todos los servidores que trabajan en la entidad (empleados, asesores, consultores o cualquier otra modalidad de contrato). Igualmente, se debe publicar la escala de viáticos.

La entidad publica los datos de contacto de toda la planta de personal, incluyendo contratistas. Los datos a publicar son: nombre completo, profesión, cargo, correo electrónico, número de teléfono. Se actualiza cuando se efectúen cambios.

La entidad publica los resultados de la evaluación a funcionarios, así como el seguimiento a los acuerdos de gestión de los funcionarios principales.

La entidad publica ofertas de empleos y prestación de servicios, con los respectivos resultados de los procesos. Se debe actualizar cuando finalicen los procesos de selección. 
